\title{
KAJIAN LITERATUR RUANG TERBUKA HIJAU TERHADAP KEBUTUHAN OKSIGEN
}

\author{
Nia Rosliana Sinambela \\ Program Studi Perencanaan Wilayah dan Kota Universitas Islam Sultan Agung \\ E-mail Korespodensi: niaroslianasinambela@gmail.com
}

\begin{abstract}
Green open space is a producer of oxygen that is needed by humans. Oxygen is a major human need for breathing and respiration, so green open space is needed by humans as humans need oxygen. The research method used in this study is the literature study. Literature that will be studied is Banda Aceh city, Depok city, Denpasar city, Manado city, Palangkaraya city, and Salatiga city. The six literature studies have different oxygen requirements and green open space. The parameters in this study are the oxygen needs of humans, motor vehicles, livestock, industry, and hotel. Based on the results of the literature study, there is one city that has fulfilled the oxygen demand in its area, but five other cities still have not met the oxygen needs of its region.
\end{abstract}

Key Word: Open Space, Oxygen Demand

\begin{abstract}
Abstrak
Ruang terbuka hijau merupakan produsen oksigen yang sangat dibutuhkan manusia. Oksigen merupakan kebutuhan utama manusia untuk melakukan pernafasan dan respirasi. Metode penelitian yang digunakan dalam penelitian ini ialah pendekatan studi literatur. Kajian literatur yang akan dikaji berada di kota Banda Aceh, kota Depok, Kota Denpasar, Kota Manado, Kota Palangkaraya, dan Kota Salatiga. Ke-enam kajian literatur tersebut memiliki kebutuhan oksigen dan ruang terbuka hijau yang berbeda-beda. Parameter yang digunakan dalam penelitian ini ialah kebutuhan oksigen manusia, kendaraan bermotor, ternak, industri, dan hotel. Berdasarkan hasil kajian literatur terdapat 1 kota yang sudah mencukupi kebutuhan oksigen di kawasannya namun 5 kota lainnya masih belum mencukupi kebutuhan oksigen kawasannya.

Kata Kunci : Ruang Terbuka, Kebutuhan Oksigen
\end{abstract}




\section{PENDAHULUAN}

Penyediaan ruang terbuka hijau di setiap wilayah memiliki aturan yang sudah diatur oleh pemerintah Indonesia. Berdasarkan Peraturan Mentri PU No.05 tahun i2008 setiap wilayah minimal harus memiliki 30\% ruang iterbuka hijau yang terbagi 20\% publik dan 10\% privat. Penetapan persentase ruang terbuka hijau ini bertujuan untuk memenuhi kebutuhan oksigen masyarakat setempat. Ruang terbuka hijau memberikan manfaat kepada manusia seperti menyerap air hujan, menahan angin, menstabilkan suhu udara agar sejuk dan memproduksi oksigen yang merupakan salah satu kebutuhan pokok manusia untuk melakukan pernapasan (Sunaryo, 2013).

Ruang terbuka hijau diidentifikasikan dengan adanya vegetasi atau tanaman. Tanaman merupakan salah satu produsen oksigen. Menurut Gerarkis dalam Kurniawan dan Anggreani (2011) $1 \mathrm{~m}^{2} \mathrm{RTH}$ (ruang terbuka hijau ) dapat memproduksi 50,625 gram oksigen $/ \mathrm{m}^{2} /$ hari, sehingga dapat disimpulkan bahwa semakin lebar ruang terbuka hijau maka semakin banyak juga oksigen yang mampu dihasilkan oleh tanaman tersebut. Setiap pohon memiliki fungsi untuk memenuhi kebutuhan oksigen untuk dua manusia (Imran,2002 dalam Kusminingrum:2008).

Ruang terbuka hijau memiliki fungsi sebagai paru-paru bumi, hal ini dikarenakan ruang terbuka hijau menghasilkan oksigen yang merupakan kebutuhan manusia untuk bertahan hidup. Tidak adanya oksigen akan merugikan manusia dibidang kesehatan, manusia akan sulit untuk bernafas jika kebutuhan oksigen tidak terpenuhi. Manusia pada umumnya membutuhkan oksigen sebanyak 600 liter/hari atau 864 g/hari. Oksigen ini digunakan untuk menghasilkan energi dalam tubuh manusia dan setelah itu tubuh manusia akan mengeluarkan karbon dioksida sebanya 480 liter/hari, sehingga terdapat oksigen yang mengendap dibagian tubuh manusia sebanyak 120 liter/hari (Muis, 2010).

\section{LITERATURE REVIEW}

\subsection{Ruang Terbuka Hijau}

Ruang terbuka merupakan ruang atau kawasan yang dapat digunakan atau dilalui masyarakat secara publik maupun khusus. Ruang terbuka hijau terdiri dari berbagai macam jenis, terdiri dari 
jalan, taman, hutan, dan trotoar (Kusuma. Dkk,2014). Menurut Undang-Undang No 26 tahun 2007 ruang terbuka hijau adalah area yang dapat berbentuk panjang, berjalur atau mengelompok, yang penggunaannya lebih bersifat terbuka, tempat tumbuh tanaman, baik yang tumbuh secara alamiah maupun yang sengaja ditanam. ruang terbuka hijau memiliki minimum luas dalam suatu kawasan, luas ruang terbuka hijau minimal 30\% dari luas suatu kawasan, 20\% RTH publik dan 10\% RTH privat (Siwi, 2018). Hal tersebut dilakukan bertujuan untuk menyeimbankan ekosistem suatu kawasan atau wilayah. Keseimbangan ekosistem yang dipertahankan merupakan fungsi hidrologis, iklim mikro, ketersediaan udara bersih agar mendapatkan udara yang baik dan estetika suatu wilayah (Baharudin, 2011 dalam Kusuma. dkk 2014). Ruang terbuka hijau merupakan salah satu elemen kota yang memiliki standar atau kriteria tertentu sehingga ruang terbuka hijau tidak dapat diabaikan dalam suatu kawasan (Rijal,2008). Ruang terbuka dapat menjadi berbagai kegiatan aktivitas mulai ekonomi, sosial dan budaya (Putri dkk, 2017; Rahman, 2020a; Rahman, 2020b). Ruang terbuka hijau merupakan salah satu dari delapan elemen arsitektur kota dan tujuan elemen yang lain adalah dukungan aktifitas, tata guna lahan, sirkulasi dan parkir, gubahan masa bangunan, serta jalur pejalan kaki atau pedestrian (Ramadhan. Dkk, 2018).

Tipologi ruang terbuka hijau menurut peraturan menteri Pekerjaan Umum Nomor 05/PRT/M/2008 terbagi menjadi berbagai jenis seperti berikut. Berikut merupakan tabel tipologi ruang terbuka hijau.

\section{Tabel 1 Tipologi Ruang Terbuka Hijau}

\begin{tabular}{|c|c|c|c|c|}
\hline \multirow{5}{*}{$\begin{array}{c}\text { Ruang } \\
\text { Terbuka } \\
\text { Hijau } \\
\text { (RTH) }\end{array}$} & Fisik & Fungsi & Struktur & kepemilikan \\
\hline & \multirow{2}{*}{ RTH Alami } & Ekologis & \multirow{2}{*}{ Pola Ekologis } & \multirow{2}{*}{ RTH Publik } \\
\hline & & Sosial budaya & & \\
\hline & \multirow{2}{*}{$\begin{array}{l}\text { RTH Non } \\
\text { Alami }\end{array}$} & Estetika & \multirow{2}{*}{$\begin{array}{c}\text { Pola } \\
\text { Planologis }\end{array}$} & \multirow[t]{2}{*}{ RTH Privat } \\
\hline & & ekonomi & & \\
\hline
\end{tabular}

Berdasarkan tabel 1 ruang terbuka hijau berdasarkan fisik terbagi atas dua, berdasarkan fungsi terbagi atas empat, berdasarkan struktur dan kepemilikan masing-masing terbagai menjadi dua. Berdasarkan fisik ruang terbuka hijau terbagi menjadi ruang terbuka hijau alami dan non-alami. Ruang terbuka hijau alami seperti taman nasional, habitat alami, dan kawasan lindung, sedangkan ruang tebuka hijau non alami berupa kebun bunga, taman, dan lapangan (Anhusadar,2018). Berdasarkan fungsi ruang terbuka hijau terbagi menjadi ekologis, sosial 
budaya, estetika, dan ekonomi. Berdasarkan struktur ruang terbuka hijau terbagi menjadi pola ekologis dan pola planologis, sedangkan berdasarkan kepemilikan ruang terbuka hijau terbagi menjadi tuang tebuka hijau publik dan privat.

\subsection{Penyediaan Ruang Terbuka Hijau}

Penyediaan ruang terbuka hijau terdapat 3 jenis yaitu berdasarkan luas wilayah, berdasarkan jumlah penduduk, dan berdasarkan tegakan vegetasi. Berikut merupakan penjelasan mengenai penyediaan ruang terbuka hijau.

\section{a) Penyediaan RTH Berdasarkan Luas Wilayah}

Ruang terbuka hijau (RTH) terdiri atas 2 jenis yaitu ruang privat (khusus) dan publik (umum). Berdasarkan Permen PU No 5/PRT/M2008 RTH suatu wilayah paling sedikit ialah $30 \%$ yang terdiri dari 20\% umum(publik) dan 10\% khusus (privat). Semakin luas RTH maka semakin banyak oksigen yang diproduksi. Adanya RTH sebanyak 30\% dari luas wilayah akan memberikan manfaat seperti memberikan keseimbangan ekosistem, memberikan udara bersih, memberikan kesan sejuk, dan memberikan nilai tambahan dalam estetika/keindahaan suatu wilayah. Akan tetapi penyediaan RTH berdasarkan luas wilayah widak begitu akurat dengan kebutuhan oksigen manusia, sehingga perlu dilakukan penelitian kebutuhan oksigen diwilayahnya.

\section{b) Penyediaan RTH Berdasarkan Jumlah Penduduk}

Penduduk merupakan salah satu pemakai ruang terbuka hijau (RTH). Ruang terbuka hijau (RTH) harus memiliki luas sesuai dengan jumlah penduduk, dengan tujuan agar dapat memberikan manfaat yang baik kepada penduduk. Luas RTH berdasarkan jumlah penduduk didapatkan melalui penyilangan jumlah penduduk dengan standar luas RTH perkapita. Berikut merupakan kriteria dan standart penentuan penyediaan ruang terbuka hijau berdasarkan jumlah penduduk.

Tabel 2 Kriteria Penentuan Penyedian Ruang Terbuka Hijau di Kawasan Perkotaan

\begin{tabular}{|l|l|l|r|r|l|}
\hline No & \multicolumn{1}{c}{$\begin{array}{c}\text { Unit } \\
\text { Lingkungan }\end{array}$} & \multicolumn{1}{c}{ Tipe RTH } & $\begin{array}{c}\text { Luas } \\
\text { Minimal/Unit } \\
(\mathbf{m} 2)\end{array}$ & $\begin{array}{c}\text { Luas } \\
\text { Minimal/Kapita } \\
(\mathbf{m} 2)\end{array}$ & \multicolumn{1}{|c|}{ Lokasi } \\
\hline 1. & 250 jiwa & Taman RT & 350 & 1,0 & $\begin{array}{l}\text { Ditengah lingkungan } \\
\text { RT }\end{array}$ \\
\hline 2. & 2.500 jiwa & Taman RW & 1.250 & 0,5 & Dipuast kehiatan RW \\
\hline 3. & 30.000 jiwa & Taman & 9.000 & 0,3 & Dikelompokan dengan \\
\hline
\end{tabular}




\begin{tabular}{|c|c|c|c|c|c|}
\hline No & $\begin{array}{c}\text { Unit } \\
\text { Lingkungan }\end{array}$ & Tipe RTH & $\begin{array}{c}\text { Luas } \\
\underset{(\mathrm{m} 2)}{\operatorname{Minimal} / \text { Unit }}\end{array}$ & $\begin{array}{c}\text { Luas } \\
\text { Minimal/Kapita } \\
(\mathrm{m} 2)\end{array}$ & Lokasi \\
\hline & & Kelurahan & & & sekolah/pusat kelurahan \\
\hline \multirow[t]{2}{*}{4.} & \multirow[t]{2}{*}{120.000 jiwa } & $\begin{array}{l}\text { Taman } \\
\text { Kecamatan }\end{array}$ & 24.000 & 0,2 & $\begin{array}{l}\text { Dikelompokan dengan } \\
\text { sekolah/pusat } \\
\text { kecamatan }\end{array}$ \\
\hline & & Pemakaman & Disesuaikan & 1,2 & Tersebar \\
\hline \multirow[t]{3}{*}{5.} & \multirow{3}{*}{480.000 jiwa } & Taman Kota & 144.000 & 0,3 & Di pusat wilayah/kota \\
\hline & & Hutan Kota & Disesuaikan & 4,0 & $\begin{array}{l}\text { Didalam/kawasan } \\
\text { pinggiran }\end{array}$ \\
\hline & & $\begin{array}{l}\text { Untuk fungsi- } \\
\text { fungsi tertentu }\end{array}$ & Disesuaikan & 12,5 & $\begin{array}{l}\text { Disesuaikan dengan } \\
\text { kebutuhan }\end{array}$ \\
\hline
\end{tabular}

Berdasarkan tabel I.2 dapat diketahui ruang terbuka hijau memiliki 5 unit lingkungan yang terbagi menjadi beberapa tipe ruang terbuka hijau. Tipe-tipe ruang terbuka hijau tersebut memiliki luas minimal per kapita maupun per unit dan ditempatkan di lokasi yang sudah ditentukan. Beberapa tipe ruang terbuka hijau tidak memiliki luas minimal seperti pemakaman, hutan kota, dan fungsi-fungsi tertentu, sedangkan tipe ruang terbuka hijau lainnya memiliki luas minimal yang sudah ditentukan oleh peraturan menteri.

\section{Lanjutan Tabel I.3}

\section{c) Penyediaan RTH Berdasarkan Tegakan Vegetasi}

Ruang terbuka hijau berdasarkan tegakan vegetasi terbagi ata 4 jenis yaitu taman lingkungan, taman kota, sungai, dan pemakaman. Ke-empat jenis ruang terbuka hijau tersebut memiliki kriteria masing-masing. Berikut merrupakan klasifikasi tegakan vegetasi ruang terbuka hijau.

\section{Tabel I. 3 Klasifikasi Tegakan Vegetasi RTH}

\begin{tabular}{|c|l|l|}
\hline No. & \multicolumn{2}{|c|}{ Jenis RTH } \\
\hline 1. & Taman lingkungan & Luas area yang ditanam tanaman min memiliki luas 70-80\% dari luas taman \\
\hline 2. & Taman kota & $\begin{array}{l}\text { Luas area yang ditanaman seperto pohon tahunan, perdu, dan semak yang } \\
\text { ditanam secara berkelompok minimal seluar 80\% dari luas taman }\end{array}$ \\
\hline 3. & Sungai & Tiga meter disamping sungai \\
\hline 4. & Pemakaman & Minimal terdapat vegetasi 100 pohon dengan jarak tanam rapat tidak beraturan \\
\hline & \multicolumn{2}{|c|}{ Sumber: PP No5 Tahun 2008 dalam Shani, 2015 } \\
\hline
\end{tabular}




\subsection{Kebutuhan Oksigen}

Oksigen merupakan kebutuhan pokok manusia untuk bertahan hidup di dunia. Manusia mengoksidasi 3000 kalori setiap hari dari makanan yang dimakannya dan menggunakan 600 liter oksigen serta memproduksi karbon dioksida sebanyak 480 liter dalam satu hari ( Wisesa dalam Irham,dkk;2017). Tidak hanya manusia saja yang membutuhkan oksigen, akan tetapi kendaraan bermotor dan hewan ternak juga perlu dihitung kebutuhan oksigennya agar tercapai ruang terbuka hijau sesuai dengan kebutuhan oksigen di wilayah tersebut. Kendaraan bermotor membutuhkan oksigen untuk membakar bahan bakar. Selain kendaraan bermotor terdapat tambahan yang sama seperti kendaraan bermotor yaitu industri yang sama sama menmbutuhkan oksigen unutk membakar bahan bakarnya. Suatu mesin industri pada umumnya menggunakan $185.759 \mathrm{~kg} / \mathrm{hari}$ oksigen dengan waktu 8 jam dan berdasarkan hitungan setiap satu kilogram bahan bakar motor diesel membutuhkan 2,86 kg oksigen. Luas ruang terbuka hijau yang dibutuhkan sesuai dengan kebutuhan oksigen manusia dalam suatu kota dapat dihitung dengan menggunakaan persamaan Gerarkis (Wisesa (1988) dalam Hanafi, N dan Pribadi, T; 2013). Berikut merupakan rumus yang akan digunakan untu menghitung kebutuhan oksigen.

\section{Keterangan:}

$$
\mathrm{Lt}=\frac{P t+K t+T t}{(54) x(0,9375)} m^{2}
$$

Lt : luas ruang tebruka hijau $(\mathrm{RTH})$ pada tahun ke-t $\left(m^{2}\right)$

Pt : jumlah kebutuhan oksigen bagi penduduk pada tahun ke-t (gram)

Kt : jumlah kebutuhan oksigen bagi kendaraan bermotor pada tahun ke-t (gram)

Tt : jumlah kebutuhan oksigen bagi ternak pada tahun ke-t (gram)

54 : merupakan tetapan yang menunjukan bahwa satu meter luas lahan menghasilkan 54 gram berat kering tanaman per hari

0,9375 :merupakan tetapan yang mneyatakan bahwa satu gram bera kering tanaman setara degan produksi oksigen 0,9375 gram.

Kendaraan bermotor terbagi menjasi 5 jenis yaitu sepeda motor, kendaraan penumpang, kendaraan ringan, kendaraan beban, dan kendaraan bus. Ke-lima jenis kendaraan tersebut memiliki kebutuhan oksigen yang berbeda-beda. Berikut merupakan kriteria dan indikator yang digunakan dalam penghitungan kebutuhan oksigen untuk kendaraan bermotor. 
Tabel 4 Jenis Kendaraan Bermotor Berdasarkan Kebutuhan Oksigen

\begin{tabular}{|c|c|c|c|c|c|c|}
\hline No. & $\begin{array}{c}\text { Jenis } \\
\text { Kendaraan }\end{array}$ & $\begin{array}{l}\text { Bahan } \\
\text { Bakar }\end{array}$ & $\begin{array}{l}\text { Kebutuhan } \\
\text { Bahan Bakar } \\
\text { (Kg/Ps jam) }\end{array}$ & $\begin{array}{c}\text { Daya } \\
\text { (PS) }\end{array}$ & $\begin{array}{c}\text { Kebutuhan } \\
\text { Oksigen per } \\
\text { Kilogram Bahan } \\
\text { Bakar }\end{array}$ & $\begin{array}{c}\text { Kebutuhan } \\
\text { Oksigen } \\
\text { (Kg/jam) }\end{array}$ \\
\hline 1 & Sepeda motor & Bensin & 0,21 & 1 & 2,77 & 0,5817 \\
\hline 2 & $\begin{array}{l}\text { Kendaraan } \\
\text { penumpang }\end{array}$ & Bensin & 0,21 & 20 & 2,77 & 11,634 \\
\hline 3 & $\begin{array}{l}\text { Kendaraan } \\
\text { ringan }\end{array}$ & Solar & 0,16 & 50 & 2,86 & 22,88 \\
\hline 4 & $\begin{array}{l}\text { Kendaraan } \\
\text { beban }\end{array}$ & Solar & 0,16 & 200 & 2,86 & 91,52 \\
\hline 5 & $\begin{array}{l}\text { Kendaraan } \\
\text { bus }\end{array}$ & Solar & 0,16 & 100 & 2,77 & 44,32 \\
\hline
\end{tabular}

Sumber:Wisesa (1998) dalam Mbele dan Setiawan (2015)

\section{Keterangan :}

a) Kendaraan bermotor : : sepeda motor biasa dan otomatis

b) Kendaraan penumpang : : : $\quad$ mobil sedan, jeep, ambulan, dsb

c) Kendaraan beban ringan : minibus

d) Kendaraan beban berat $\quad$ : truck dan mobil pemadam kebakaran

e) Kendaraan bus : bus

Hewan ternak juga membutuhkan oksigen untuk keberlangsungan hidup di dunia, tidak hanya manusia dan kendaraan bermotor. Jenis ternak yang dimaksud ialah sapi, kambing, domba, kerbau, kuda, babi, dan unggas. Ke-tujuh jenis ternah tersebut memiliki kebutuhan oksigen yang berbeda-beda. Berikut merupakan kebutuhan oksigen hewan ternak .

Tabel 5 Jenis Ternak Berdasarkan Kebutuhan Oksigen

\begin{tabular}{|c|c|c|c|}
\hline \multirow[t]{2}{*}{ No. } & \multirow[t]{2}{*}{ Jenis ternak } & \multicolumn{2}{|c|}{ Kebutuhan Oksigen } \\
\hline & & Liter/hari & Kg/hari \\
\hline 1 & Sapi & 1182 & 1,7 \\
\hline 2 & Kambing & 218 & 0,31 \\
\hline 3 & Domba & 218 & 0,31 \\
\hline 4 & Kerbau & 1182 & 1,7 \\
\hline 5 & Kuda & 1288 & 2,86 \\
\hline 6 & Babi & 548 & 1,24 \\
\hline 7 & Unggas & 205,187 & 0,17 \\
\hline
\end{tabular}




\subsection{Variabel, Indikator, dan Parameter}

Sub bab ini membahas variabel, indikator, dan parameter yang digunakan dalam kajian pustaka ini. Variabel merupakan konsep yang digunakan dalam kajian pustaka ini yang berfungsi sebagai acuan dalam melakukan studi literatur pada penelitian ini. Indikator merupakan bagian dari variabel yang diperjelas melalui parameter yang berfungsi sebagai alat untuk mengidentifikasi indikator yang digunakan.

Tabel 6 Variabel, Indikator, dan Parameter

\begin{tabular}{|c|c|c|c|c|c|}
\hline No. & \multicolumn{2}{|c|}{ VARIABEL } & INDIKATOR & PARAMETER & TEORI \\
\hline 1 & \multirow{12}{*}{$\begin{array}{l}\text { Ruang } \\
\text { Terbuka } \\
\text { Hijau }\end{array}$} & $\begin{array}{l}\text { Berdasarkan } \\
\text { luas }\end{array}$ & Luas wilayah & $\begin{array}{l}30 \% \text { dari luas } \\
\text { wilayah }\end{array}$ & $\begin{array}{l}\text { PP NO } 5 \text { TAHUN } \\
2008\end{array}$ \\
\hline \multirow[t]{2}{*}{2} & & $\begin{array}{l}\text { Berdasarkan } \\
\text { kepemilikan }\end{array}$ & RTH publik & $\begin{array}{l}20 \% \text { dari luas } \\
\text { wilayah }\end{array}$ & \multirow[t]{2}{*}{$\begin{array}{l}\text { Sumarauv, A.N } \\
(2016)\end{array}$} \\
\hline & & & RTH privat & $\begin{array}{l}10 \% \text { dari luas } \\
\text { wilayah }\end{array}$ & \\
\hline \multirow[t]{7}{*}{3} & & $\begin{array}{l}\text { Berdasarkan } \\
\text { kependudukan }\end{array}$ & 250 jiwa & $\begin{array}{l}250 m^{2} \text { taman } \\
\text { RT }\end{array}$ & \multirow[t]{7}{*}{ Siwi, nunung (2018) } \\
\hline & & & 2.500 jiwa & $\begin{array}{l}1.250 m^{2} \text { taman } \\
\text { RW }\end{array}$ & \\
\hline & & & 30.000 jiwa & $\begin{array}{l}9.000 m^{2} \text { taman } \\
\text { kelurahan }\end{array}$ & \\
\hline & & & 120.000 jiwa & $\begin{array}{l}24.000 m^{2} \\
\text { taman } \\
\text { kecamatan }\end{array}$ & \\
\hline & & & 480.000 jiwa & $\begin{array}{l}144.000 m^{2} \\
\text { taman kota }\end{array}$ & \\
\hline & & & Kecamatan & $\begin{array}{l}\text { (menyesuaikan) } \\
\text { pemakaman }\end{array}$ & \\
\hline & & & $\begin{array}{l}\text { Bagian wilayah } \\
\text { kota }\end{array}$ & $\begin{array}{l}\text { (menyesuaikan) } \\
\text { hutan } \\
\text { kota/fungsi } \\
\text { tertentu }\end{array}$ & \\
\hline \multirow[t]{2}{*}{4} & & $\begin{array}{l}\text { Berdasarkan } \\
\text { tegak vegetasi }\end{array}$ & $\begin{array}{l}\text { Taman } \\
\text { lingkungan }\end{array}$ & $\begin{array}{l}\text { Luas area } \\
\text { minimal } \\
\text { diatanami } \\
\text { dengan } \\
\text { tanaman } \\
\text { sebanyak } 70- \\
80 \%\end{array}$ & \multirow[t]{2}{*}{ Shani, FM (2015) } \\
\hline & & & Taman kota & $\begin{array}{l}\text { Luas area harus } \\
\text { ditanami pohon } \\
\text { tahunan, perdu, }\end{array}$ & \\
\hline
\end{tabular}




\begin{tabular}{|c|c|c|c|c|c|}
\hline \multirow[t]{4}{*}{ No. } & \multicolumn{2}{|c|}{ VARIABEL } & INDIKATOR & PARAMETER & TEORI \\
\hline & & & & $\begin{array}{l}\text { dan semak } \\
\text { ditanam secara } \\
\text { berkelompok } \\
\text { seluas } 80 \% \text { dari } \\
\text { luas taman }\end{array}$ & \\
\hline & & & Sungai & $\begin{array}{l}3 \text { meter } \\
\text { disamping } \\
\text { sungai ditanam } \\
\text { tanaman }\end{array}$ & \\
\hline & & & Pemakaman & $\begin{array}{l}\text { Vegetasi } \\
\text { minimal } 100 \\
\text { pohon dengan } \\
\text { jarak tanam } \\
\text { rapat yan tidak } \\
\text { beraturan }\end{array}$ & \\
\hline 5 & Oksigen & Manusia & Manusia & $\begin{array}{l}600 \text { liter/hari } \\
\text { atau } 8,64 \\
\mathrm{~kg} / \text { hari }\end{array}$ & Muis, BA (2010) \\
\hline \multirow[t]{4}{*}{6} & & Kendaraan & Sepeda motor & $0,5817 \mathrm{~kg} / \mathrm{jam}$ & \multirow{5}{*}{$\begin{array}{l}\text { Mblewe, Maria FB } \\
\text { dan Setiawan, Rulli P } \\
(2015)\end{array}$} \\
\hline & & bermotor & $\begin{array}{l}\text { Kendaraan } \\
\text { penumpang }\end{array}$ & $11,634 \mathrm{~kg} / \mathrm{jam}$ & \\
\hline & & & $\begin{array}{l}\text { Kendaraan } \\
\text { ringan }\end{array}$ & $22,88 \mathrm{~kg} / \mathrm{jam}$ & \\
\hline & & & $\begin{array}{l}\text { Kendaraan } \\
\text { beban berat }\end{array}$ & $91,52 \mathrm{~kg} / \mathrm{jam}$ & \\
\hline \multirow[t]{8}{*}{7} & & & Kendaraan bus & $44,32 \mathrm{~kg} / \mathrm{jam}$ & \\
\hline & & \multirow[t]{7}{*}{ Ternak } & Sapi & $1,7 \mathrm{~kg} / \mathrm{hari}$ & \multirow{7}{*}{$\begin{array}{l}\text { Purwarik, Sri; } \\
\text { Sasmito, } \\
\text { Bandi;Hani'ah(2014) }\end{array}$} \\
\hline & & & Kambing & $0,31 \mathrm{~kg} /$ hari & \\
\hline & & & Domba & $0,31 \mathrm{~kg} / \mathrm{hari}$ & \\
\hline & & & Kerbau & $1,7 \mathrm{~kg} / \mathrm{hari}$ & \\
\hline & & & Kuda & $2,86 \mathrm{~kg} / \mathrm{hari}$ & \\
\hline & & & Babi & $1,24 \mathrm{~kg} / \mathrm{hari}$ & \\
\hline & & & unggas & $0,17 \mathrm{~kg} /$ hari & \\
\hline
\end{tabular}

Sumber: Analisis Penulis;2019

\section{METODOLOGI}

Kajian Pustaka kebutuhan ruang terbuka hijau berdasarkan kebutuhan oksigen menggunakan pendekatan studi literatur. Studi literatur merupakan analisis yang mengumpulkan berbagai macam buku, jurnal, paper, atau lainnya dengan tema yang sama. Melalui analisis studi literatur peneliti akan mengetahui perbandingnan masing-masing literatur yang digunakan dalam menyelesaikan penelitian ini. Studi literatur utama dalam 
penelitian analisis kebutuhan ruang terbuka hijau terdapat 6 kajian studi yang memiliki kajian wilayah yang berbeda-beda, yaitu Banda Aceh, Depok, Denpasar, Manado, Palangkaraya, dan Salatiga. Kajian studi tersebut digunakan agar menghasilkan perbedaan yang signifikan antar daerah. Sehingga, peneliti dapat membandingkan kondisi ruang terbuka hijau di masingmasing kota.

\section{HASIL DAN PEMBAHASAN}

Hasil dan pembahasan pada sub bab ini akan membahas ruang terbuka yang ada di enam jurnal yang digunakan. Ke-enam jurnal tersebut berada di daerah Banda Aceh, Depok, Denpasar, Manado, Palangkaraya, dan Salatiga. Jurnal-jurnal tersebut berada di enam lokasi yang berbeda sehingga dapat dibandingkan satu sama lain. Berikut merupakan pembahasan dari ke-enam jurnal tersebut.

\subsection{Kota Banda Aceh}

Penelitian kebutuhan ruang terbuka hijau terhadap kebutuhan oksigen di kota Banda Aceh menggunakan 2 data yaitu data sekunder dan primer, data sekunder didapatkan melalui kaji pustaka sedangkan data primer didapatkan melalui observasi. Data primer yang digunakan ialah data tipe ruang terbuka hijau dan literatur mengenai ruang terbuka hijau, sedangkan data sekunder yang digunakan ialah data jumlah penduduk, kendaraan bermotor, citra satelit kota Banda Aceh, dan data peraturan perundangan tentang ruang terbuka hijau. Analisis yang digunakan dalam penelitian ini ialah persamaan gerarkis. Metode penelitian yang digunakan oleh penulis ialah deskriptif kuantitatif. Penulis melakukan analisis pada 2 subyek yaitu penduduk atau manusia dan kendaraan bermotor.

Kota Banda Aceh memiliki luas ruang terbuka hijau sebesar $\pm 671,08$ Ha dari luas 6.135,9 Ha, sehingga luas ruang terbuka hijau di kota Banda Aceh sebesar 10.94\%. Status kepemilikan ruang terbuka hijau Kota Banda Aceh ialah ruang terbuka hijau publik yang terdiri dari taman kota, lapangan olahraga, jalur hijau jalan, makam,dan telaga/waduk/bozem. Kota Banda Aceh pada tahun 2015 memiliki jumlah penduduk sebanyak 253.499 jiwa sehingga membutuhkan $48.000 \mathrm{~m}^{2}$ ruang terbuka hijau dan membutuhkan oksigen sebanyak 219.000 kg/hari, selain itu jumlah kendaraan Kota Banda Aceh dibedakan menjadi beberapa jenis seperti bus dengan jumlah 13.108, kendaraan beban dengan jumlah 5.871, kendaraan 
penumpang dengan jumlah 5.682 dan sepeda motor dengan jumlah 82.247, sehingga total kebutuhan oksigen yang dibutuhkan kendaraan bermotor di Kota Banda Aceh ialah 2.674.000. Oksigen yang dibutuhkan manusia dan kendaraan bermotor di Kota Banda Aceh ialah 2.893.000 kg/hari sehingga total luas ruang terbuka hijau yang dibutuhkan ialah $5.715 \mathrm{Ha}$ (Irham, dkk (2017)).

\subsection{Kota Depok}

Penelitian kebutuhan ruang terbuka hijau terhadap oksigen di kota Depok menggunakan dua data yaitu data sekunder dan primer, data sekunder didapatkan melalui kaji pustaka sedangkan data primer didapatkan melalui observasi. Data primer yang digunakan ialah data sosial budaya dan ekonomi sedangkan data sekunder yang digunakan ialah data jumlah penduduk, jumlah kendaraan bermotor, dan jumlah hewan ternak serta peta rupabumi administrasi kota Depok. Analisis yang digunakan dalam penelitian ini ialah hirarki dan analisis persamaan gerarkis. Metode penelitian yang digunakan penulis ialah deskriptif kuantitatif. Penulis melakukan analisis pada 3 subyek yaitu penduduk atau manusia, kendaraan bermotor dan hewan ternak.

Kota Depok memiliki luas ruang terbuka hijau sebesar 5.125,4 Ha dari luas $20.029 \mathrm{Ha}$, sehingga luas ruang terbuka hijau 25,59\%. Status kepemilikan ruang terbuka hijau Kota Depok ialah ruang terbuka hijau publik yang terdiri dari hutan kota, jalur hijau, taman kota, areal pemakaman, sawah irigasi, kebun, situ, dan danau. Kota Depok pada tahun 2015 memiliki jumlah penduduk sebanyak 1.993.876 jiwa sehingga seharusnya membutuhkan ruang terbuka hijau seluas 519.162,8 $\mathrm{m}^{2}$ ruang terbuka hijau dan membutuhkan oksigen sebanyak $1.722 .708 \mathrm{~kg} /$ hari. Selain manusia terdapat kendaraan bermotor dan hewan ternah yang membutuhkan oksigen juga. Kendaraan bermotor di Kota Depok berjumlah sebanyak 18.915 sehingga membutuhkan oksigen sebanyak 523.536 kg/hari. Kota Depok juga memiliki hewan ternah dengan jumlah 4.702.013 sehingga membutuhkan oksigen sebanyak 821.345 $\mathrm{kg} /$ hari. Berdasarkan jumlah manusia, kendaraan bermotor, dan hewan ternak yang ada di Kota Depok diketahui jumlah oksigen yang dibutuhkan sebanyak $2.650 .397 \mathrm{~kg} / \mathrm{hari}$ sehingga luas ruang terbuka hijau yang dibutuhkan ialah sebanyak 6.059 Ha (Muis, B.A(2016). 


\subsection{Kota Denpasar}

Penelitian kebutuhan ruang terbuka hijau terhadap kebutuhan oksigen di Kota Denpasar menggunakan dua data yaitu data primer dan data sekunder. Data primer didapatkan melalui observasi dan data sekunder didapat melalui kaji pustaka. Data primer yang digunakan data hasil observasi kesesuaian lahan, sedangkan data sekunder yang digunakan ialah citra ALOS AVNIR-2, citra Quickbird, dan Peta RBI serta data kependudukan, kendaraan bermotor, dan industri. Analisis yang digunakan dalam penelitian ini ialah analisis radiometrik \& geometrik serta analisis persamaan gerarkis. Metode penelitian yang digunakan penulis ialah deskriptif kuantitatif. Penulis melakukan analisis pada 3 subyek yaitu penduduk atau manusia, kendaraan bermotor dan industri.

Kota Denpasar memiliki ruang terbuka hijau sebesar $1.868,35 \mathrm{Ha}$ atau 38,92\% dari luas wilayah Kota Denpasar. Kota Denpasar memiliki jumlah penduduk sebanyak 846.200 jiwa yang membutuhkan oksigen sebanyak 740.082,5 kg/hari. Penduduk Kota Denpasar memiliki kendaraan bermotor dan indutri, untuk menjalankan mesin mesin yang digunakan dikendaraan bermotor dan industri membutuhkan oksigen untuk menjalankannya. Kendaraan bermotor kota Denpasar membutuhkan oksigen sebanyak 585.718,5 kg/hari dan industri membutuhkan oksigen sebanyak $116.879,5 \mathrm{~kg} /$ hari. Sehingga total oksigen yang dibutuhkan Kota Denpasar ialah 1.442.680,62 kg/hari, berdasarkan jumlah oksigen tersebut maka diketahui jumlah ruang terbuka hijau yang dibutuhkan yaitu 2.894,71 Ha (Putrajaya, I Ketut (2017).

\subsection{Kota Manado}

Penelitian kebutuhan ruang terbuka hijau terhadap oksigen di kota Manado menggunakan 1 data yaitu hanya data sekunder yang diperoleh malalui kaji pustaka. Data sekunder yang digunakan ialah data statistik seperti kependudukan, kendaraan bermotor, dan hewan ternak, selain itu juga menggunakan data batas administrasi kota Manado, Peta RBI, dan citra EO-1 ALI. Analisis yang digunakan dalam penelitian ini ialah analisis persamaan gerarkis. Metode penelitian yang digunakan penulis ialah deskriptif kuantitatif. Penulis melakukan analisis pada 4 subyek yaitu penduduk atau manusia, kendaraan bermotor dan hewan ternak serta genset hotel. 
Kota Manado memiliki ruang terbuka hijau seluas 3.967,54 Ha dari luas 16.516,98 Ha. Jenis ruang terbuka hijau yang ada di Kota Manado ialah ruang terbuka hijau publik dengan jenis perkebunan kelapa, semak belukar, kebun campuran, vegetari rerumputan, padang golf, dan alang alang. Kota Manado pada tahun 2010 memiliki jumlah penduduk sebanyak 439.660 jiwa sehingga membutuhkan ruang terbuka hijau sebesar $131.898 \mathrm{~m}^{2}$ dan juga membutuhkan oksigen sebanyak 379.866 kg/hari. Kota Manado memiliki jumlah kendaraan sebanyak 28.062 kendaraan yang terdiri dari mobil penumpang dan mikrolet, mobil barang, bus, kendaraan pribadi, dan motor. Semua kendaraan-kendaraan tersebut membutuhkan oksigen sebanyak $37.308,36 \mathrm{~kg} /$ hari. Selain manusia dan kendaraan bermotor terdapat hewan ternak yang juga membutuhkan oksigen. Kota Manado memiliki hewan ternak sebanyak 153.229 hewan dan membutuhkan oksigen sebanyak $34.490 \mathrm{~kg} /$ hari . Berdasarkan jumlah kebutuhan oksigen Kota Manado membutuhkan luas ruang terbuka hijau sebesar 739,56 Ha (Hardika, Putra E (2012).

\subsection{Kota Palangkaraya}

Penelitian kebutuhan ruang terbuka hijau di kota Palangkaraya menggunakan satu data yaitu data sekunder. Data sekunder yang digunakan ialah data biofisik luas wilayah, data kependudukan, dan kendaraan bermotor. Analisis yang digunakan dalam penelitian ini ialah persamaan gerarkis. Metode penelitian yang digunakan penulis ialah deskriptif kuantitatif. Penulis melakukan analisis pada 2 subyek yaitu penduduk atau manusia, dan kendaraan bermotor.

Kota Palangkaraya memiliki luas ruang terbuka hijau sebesar 88.38 ha dari luas wilayah sebesar $267.851 \mathrm{Ha}$ sehingga luas ruang terbuka hijau Kota Palangkaraya sebesar 29,9\%. Status kepemilikan ruang terbuka hijau yang ada di Kota Palangkaraya mayoritas ialah publik yang terdiri dari taman wisata Bukit Tengkiling, kawasan perlindungan dan pelestarian hutan, kawasan lahan gambut tebal, dan sempadan sungai. Kota Palangkaraya pada tahun 2010 memiliki jumlah penduduk Kota Palangkaraya ialah 220.962 jiwa sehingga membutuhkan ruang terbuka hijau seluas $44.192 \mathrm{~m}^{2}$ dan membutuhkan oksigen sebanyak $190.911,17 \mathrm{~kg} /$ hari. Selain manusia yang membutuhkan oksigen terdapat kendaraan bermotor yang membutuhkan oksigen juga. Kendaraan bermotor Kota Palangkaraya membutuhkan oksigen sebanyak 599.393,51 kg/hari yang terbagi atas sepeda motor dengan jumlah 
$147.458,62 \mathrm{~kg} / \mathrm{hari}$, mobil penumpang dengan jumlah $241.776,07 \mathrm{~kg} / \mathrm{hari}$, mobil bebas dengan jumlah 196.379,04 kg/hari dan yang terakhir ialah bus dengan jumlah 13.779,78 kg/hari. Setelah mengetahui kebutuhan oksigen yang ada di Kota Palangkaraya dapat ditentukan luas ruang terbuka hijau yang dibutuhkan ialah 1.561,10 Ha ( Ardani, dkk (2013).

\subsection{Kota Salatiga}

Penelitian kebutuhan ruang terbuka hijau terhadap oksigen di kota Salatiga hanya menggunakan satu data yaitu data sekunder. Data sekunder yang digunakan ialah data citra quickbird, perta administrasi dan pola ruang kota Salatiga, data peta jaringan jalan dan sungai, serta data statistik seperti kependudukan, kendaraan bermotor, dan hewan ternak. Analisis yang digunakan dalam penelitian ini ialah analisis persamaan gerarkis. Metode penelitian yang digunakan penulis ialah deskriptif kuantitatif. Penulis melakukan analisis pada 3 subyek yaitu penduduk atau manusia, kendaraan bermotor dan hewan ternak.

Kota Salatiga memiliki luas ruang terbuka hijau sebesar 910,58 Ha yang terdiri dari 493,96 ha ruang terbuka hijau publik atau 8,85\% dari luas wilayah dan 416,61 ha luas ruang terbuka hijau privat atau 7,46\% dari luas wilayah. ruang terbuka hijau di Kota Salatiga terdiri dari hutan kota, jalur hijau, pemakaman, sempadan sungai, dan kawasan perlindungan dibawahnya. Kota salatiga pada tahun 2014 memiliki jumlah oenduduk sebanyak 186.087 jiwa sehingga membutuhkan ruang terbuka hijau seluas $55.826 \mathrm{~m}^{2}$ dan membutuhkan oksigen sebanyak 160.779,17 kg/hari. Kendaraan bermotor di Kota Salatiga memiliki jumlah sebanyak 399.690 kendaraan yang terdiri dari sepeda motor, kendaraan penumpang, kendaraan beban berat, kendaraan beban ringan, dan bus. Semua jenis kenadaraan tersebut membutuuhkan total oksigen sebanyak 3.268.522,81 kg/hari. Selain manusia dan kendaraan bermotor terdapat juga hewat ternah yang membutuhkan oksigen, hewan ternak di Kota Salatiga membutuhkan oksigen sebanyak 66.507,62 kg/hari, sehingga secara keseluruan kota Salatiga membutuhkan oksigen sebanyak 3.495.809,59 kg/hari sehingga membutuhkan ruang terbuka hijau sebesar 3.452,65 Ha (Purwatik, dkk (2014). 


\subsection{Kajian Studi Ruang Terbuka Hijau Terhadap Kebutuhan Oksigen}

Sub bab ini akan membahas perbandingan ruang terbuka hijau terhadap kebutuhan oksigen diantara 6 daerah yang berbeda-beda, untuk mengetahui lebih jelasnya berikut merupakan tabel matriks kajian studi yang berbeda-beda.

Tabel IV. 1 Ringkasan Kajian Studi Ruang Tebruka Hijau Terhadap Oksigen

\begin{tabular}{|c|c|c|c|c|c|c|}
\hline \multirow[t]{2}{*}{ INDIKATOR } & \multicolumn{6}{|c|}{ WILAYAH KAJIAN STUDI } \\
\hline & $\begin{array}{c}\text { BANDA } \\
\text { ACEH }\end{array}$ & DEPOK & DENPASAR & MANADO & $\begin{array}{l}\text { PALANGKA } \\
\text { RAYA }\end{array}$ & SALATIGA \\
\hline $\begin{array}{l}\text { Perolehan } \\
\text { data }\end{array}$ & $\begin{array}{l}\text { Kajian pustaka } \\
\text { dan survey } \\
\text { lapangan }\end{array}$ & $\begin{array}{l}\text { Kajian pustaka } \\
\text { dan survey } \\
\text { lapangan }\end{array}$ & $\begin{array}{l}\text { Kajian pustaka } \\
\text { dan survey } \\
\text { lapangan }\end{array}$ & Kajian pustaka & Kajian pustaka & Kajian pustaka \\
\hline $\begin{array}{l}\text { Data yang } \\
\text { diguanak }\end{array}$ & 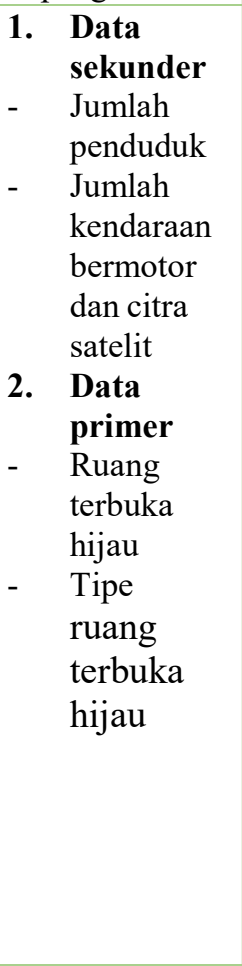 & 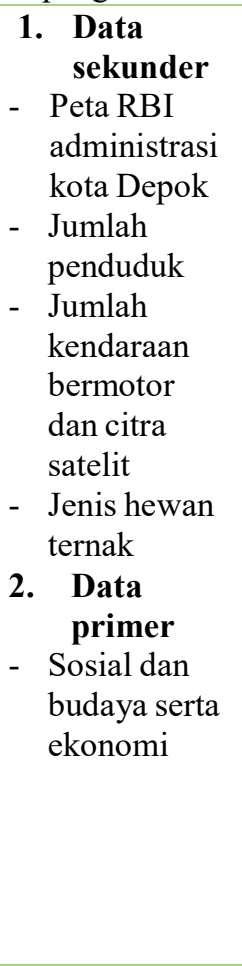 & $\begin{array}{ll}\text { 1. } & \text { Data } \\
& \text { sekunder } \\
\text { - } & \text { Citra } \\
\text { ALOS } & \text { AVNIR-2 } \\
\text { - } & \text { Citra } \\
& \text { Quickbird } \\
\text { - } & \text { Peta RBI } \\
\text { 2. Data } & \text { primer } \\
\text { - Kesesuaian } \\
\text { penggunaan } \\
\text { lahan } \\
\text { - Jumlah } \\
\text { kependuduk } \\
\text { an, } \\
\text { kendaraan } \\
\text { bermotor, } \\
\text { dan industri }\end{array}$ & $\begin{array}{cl}\text { 1. } & \text { Data sekunder } \\
\text { - } & \text { Statistik } \\
& \text { kependudukan } \\
\text { - } & \text { Statistik } \\
& \text { kendaraan } \\
& \text { bermotor } \\
\text { - } & \text { Statistik } \\
& \text { hewan ternak }\end{array}$ & $\begin{array}{l}\text { 1. Data } \\
\text { sekunder } \\
\text { - } \text { Data biofisik } \\
\text { luas wilayah } \\
\text { - } \text { Jumlah } \\
\text { penduduk } \\
\text { - Jumlah } \\
\text { kendaraan } \\
\text { - Jumlah dan } \\
\text { jenis hewan } \\
\text { ternak }\end{array}$ & $\begin{array}{ll}\text { 1. } & \text { Data } \\
\text { sekunder } \\
\text { - } & \text { Citra } \\
\text { quickbird } \\
\text { - } & \text { Citra } \\
\text { salatiga } & \text { (google } \\
\text { earth) } & \text { Perta } \\
\text { - } & \text { administra } \\
\text { si dan pola } \\
\text { ruang } \\
\text { Salatiga } \\
\text { Pera } \\
\text { jaringan } \\
\text { jalan dan } \\
\text { sungai } \\
\text { Jumlah } \\
\text { penduduk } \\
\text { Jumlah } \\
\text { ternak dan } \\
\text { jumlah } \\
\text { kendaraan } \\
\text { pribadi }\end{array}$ \\
\hline $\begin{array}{l}\text { Analisis } \\
\text { yang } \\
\text { digunakan }\end{array}$ & $\begin{array}{l}\text { Analisis } \\
\text { Persamaan } \\
\text { gerarkis }\end{array}$ & $\begin{array}{l}\text { Analisis } \\
\text { hirarki dan } \\
\text { persamaan } \\
\text { gerarkis }\end{array}$ & $\begin{array}{l}\text { Analisis } \\
\text { radiometrik \& } \\
\text { geometrik dan } \\
\text { persamaan } \\
\text { gerarkis }\end{array}$ & $\begin{array}{l}\text { Analisis persamaan } \\
\text { gerarkis }\end{array}$ & $\begin{array}{l}\text { Analisis } \\
\text { persamaan } \\
\text { gerarkis }\end{array}$ & $\begin{array}{l}\text { Analisis } \\
\text { persamaan } \\
\text { gerarkis }\end{array}$ \\
\hline $\begin{array}{l}\text { Metode } \\
\text { penelitian }\end{array}$ & $\begin{array}{l}\text { Deskripitf } \\
\text { kuantitatif }\end{array}$ & $\begin{array}{l}\text { Deskripitf } \\
\text { kuantitatif }\end{array}$ & $\begin{array}{l}\text { Deskripitf } \\
\text { kuantitatif }\end{array}$ & $\begin{array}{l}\text { Deskripitf } \\
\text { kuantitatif }\end{array}$ & $\begin{array}{l}\text { Deskripitf } \\
\text { kuantitatif }\end{array}$ & $\begin{array}{l}\text { Deskripitf } \\
\text { kuantitatif }\end{array}$ \\
\hline $\begin{array}{l}\text { Parameter } \\
\text { penelitian }\end{array}$ & $\begin{array}{l}\text { Manusia dan } \\
\text { kendaraan } \\
\text { bermotor }\end{array}$ & $\begin{array}{l}\text { Manusia, } \\
\text { kendaraan } \\
\text { bermotor, dan } \\
\text { hewan ternak }\end{array}$ & $\begin{array}{l}\text { Manusia, } \\
\text { kendaraan } \\
\text { bermotor, dan } \\
\text { industri }\end{array}$ & $\begin{array}{l}\text { Manusia, } \\
\text { kendaraan } \\
\text { bermotor, hewan } \\
\text { ternak, dan hotel }\end{array}$ & $\begin{array}{l}\text { Manusia, } \\
\text { kendaraan } \\
\text { bermotor, dan } \\
\text { hewan ternak }\end{array}$ & $\begin{array}{l}\text { Manusia, } \\
\text { kendaraan } \\
\text { bermotor, dan } \\
\text { hewan ternak }\end{array}$ \\
\hline $\begin{array}{l}\text { Rumus } \\
\text { Penelitian } \\
\left(m^{2}\right)\end{array}$ & $\begin{array}{l}\frac{X t+Y t}{(54) x(0,9375)} \\
\text { Xt:jumlah } \\
\text { kebutuhan }\end{array}$ & $\begin{array}{l}\frac{P t+K t+T t}{(54) x(0,9375)} \\
\text { Pt: jumlah } \\
\text { kebutuhan }\end{array}$ & $\begin{array}{l}\frac{P t+K t+I t}{(54) x(0,9375)} \\
\text { Pt: jumlah } \\
\text { kebutuhan }\end{array}$ & $\begin{array}{l}\frac{A t+B t+C t+D t}{(54) x(0,9375)} \\
\text { At: jumlah } \\
\text { kebutuhan oksigen }\end{array}$ & $\begin{array}{l}\frac{P t+K t}{(54) x(0,9375)} \\
\text { Pt: jumlah } \\
\text { kebutuhan }\end{array}$ & $\begin{array}{l}\frac{P t+K t+T t}{(54) x(0,9375)} \\
\text { Pt: jumlah } \\
\text { kebutuhan }\end{array}$ \\
\hline
\end{tabular}




\begin{tabular}{|c|c|c|c|c|c|c|}
\hline \multirow[t]{2}{*}{ INDIKATOR } & \multicolumn{6}{|c|}{ WILAYAH KAJIAN STUDI } \\
\hline & $\begin{array}{l}\text { BANDA } \\
\text { ACEH }\end{array}$ & DEPOK & DENPASAR & MANADO & $\begin{array}{c}\text { PALANGKA } \\
\text { RAYA }\end{array}$ & SALATIGA \\
\hline & $\begin{array}{l}\text { oksigen } \\
\text { manusia pada } \\
\text { tahun } \mathrm{t} \\
\text { Yt: jumlah } \\
\text { kebutuhan } \\
\text { oksigen } \\
\text { kendaraan } \\
\text { bermotor pada } \\
\text { tahun } \mathrm{t}\end{array}$ & $\begin{array}{l}\text { oksigen } \\
\text { manusia pada } \\
\text { tahun t } \\
\text { Kt: jumlah } \\
\text { kebutuhan } \\
\text { oksigen } \\
\text { kendaraan } \\
\text { bermotor pada } \\
\text { tahun t } \\
\text { Tt: jumlah } \\
\text { kebutuhan } \\
\text { oksigen hewan } \\
\text { ternak oada } \\
\text { tahun t }\end{array}$ & $\begin{array}{l}\text { oksigen } \\
\text { manusia pada } \\
\text { tahun } \mathrm{t} \\
\text { Kt: jumlah } \\
\text { kebutuhan } \\
\text { oksigen } \\
\text { kendaraan } \\
\text { bermotor pada } \\
\text { tahun } \mathrm{t} \\
\text { It: jumlah } \\
\text { kebutuhan } \\
\text { oksigen } \\
\text { industri pada } \\
\text { tahun } \mathrm{t}\end{array}$ & $\begin{array}{l}\text { manusia pada tahun } \\
\mathrm{t} \\
\text { Bt: jumlah } \\
\text { kebutuhan oksigen } \\
\text { kendaraan bermotor } \\
\text { pada tahun } \mathrm{t} \\
\text { Ct: jumlah } \\
\text { kebutuhan oksigen } \\
\text { hewan ternak pada } \\
\text { tahun } \mathrm{t} \\
\text { Dt: jumlah } \\
\text { kebutuhan oksigen } \\
\text { genset hotel pada } \\
\text { tahun } \mathrm{t}\end{array}$ & $\begin{array}{l}\text { oksigen } \\
\text { manusia pada } \\
\text { tahun } \mathrm{t} \\
\text { Kt: jumlah } \\
\text { kebutuhan } \\
\text { oksigen } \\
\text { kendaraan } \\
\text { bermotor pada } \\
\text { tahun } \mathrm{t}\end{array}$ & $\begin{array}{l}\text { oksigen } \\
\text { manusia pada } \\
\text { tahun } \mathrm{t} \\
\text { Kt: jumlah } \\
\text { kebutuhan } \\
\text { oksigen } \\
\text { kendaraan } \\
\text { bermotor pada } \\
\text { tahun } \mathrm{t} \\
\text { Tt: jumlah } \\
\text { kebutuhan } \\
\text { oksigen hewan } \\
\text { ternak pada } \\
\text { tahun } \mathrm{t}\end{array}$ \\
\hline $\begin{array}{l}\text { Luas RTH } \\
\text { Eksisting } \\
\text { (ha) }\end{array}$ & 671,08 & $5.125,4$ & $1.868,35$ & $3.967,54$ & 88,38 & 185,759 \\
\hline $\begin{array}{l}\text { Oksigen } \\
\text { yang } \\
\text { dibutuhkan } \\
\text { (kg/hari) }\end{array}$ & 2.674 .000 & 2.650 .397 & $1.442 .680,62$ & 379.866 & $790.304,68$ & $3.495 .809,59$ \\
\hline $\begin{array}{l}\text { Luas RTH } \\
\text { yang } \\
\text { dibutuhkan } \\
\text { (ha) }\end{array}$ & 5.715 & 6.059 & $2.894,71$ & 739,56 & 1561,1 & $3.452,65$ \\
\hline
\end{tabular}

Sumber:Hasil Analisis, 2019

\subsection{Konsep Analisis Ruang Terbuka Hijau Berdasarkan Kebutuhan Oksigen}

Konsep analisis ruang terbuka hijau berdasarkan kebutuhan oksigen membahas teori apa saja yang digunakan seperti parameter yang digunakan untuk mencapai tujuan dengan menggunakan analisis yang ditentukan. Berikut merupakan konsep analisis yang digunakan dalam penelitian ruang terbuka hijau berdasarkan kebutuhan oksigen. 


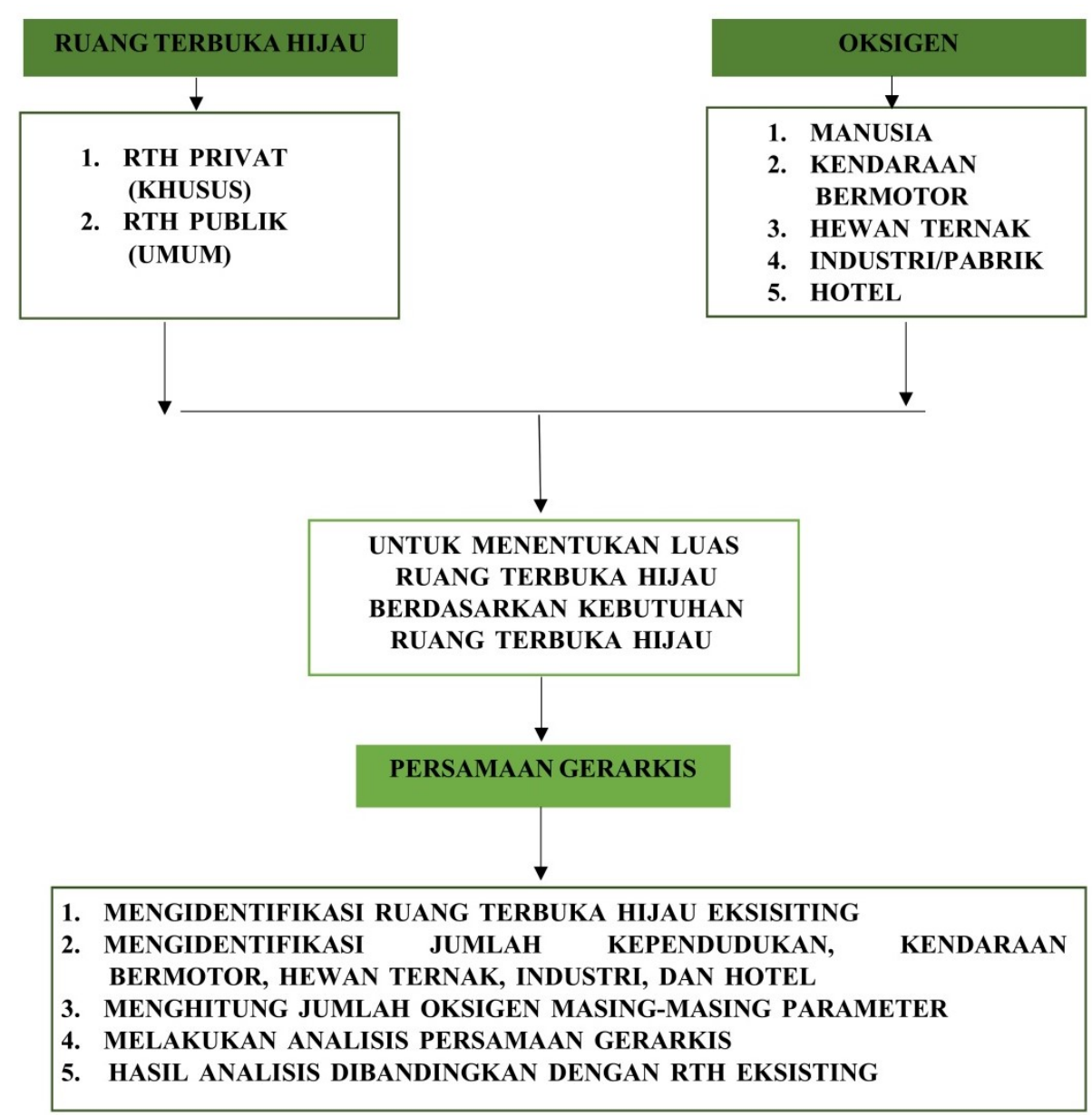

Sumber: Hasil Analisis Penulis, 2020

Gambar 4. 1 Konsep Analisis Ruang Terbuka Hijau Terhadap Kebutuhan Oksigen

\section{KESIMPULAN}

Ruang terbuka hijau merupakan produsen oksigen yang sangat dibutuhkan oleh manusia. Berdasarkan 6 kajian wilayah studi yang berada di Banda Aceh, Depok, Denpasar, Manado, Palangkaraya, dan Salatiga dapat diketahui beberapa aspek yang dapat disimpulkan. Data-data yang digunakan dalam mengolah data pada umumnya merupakan data sekunder dengan menggunakan kajian pustaka. Data-data pokok yang digunakan didalam 6 jurnal yang dikaji ialah data jumlah penduduk, dan jumlah kendaraan. Data lainnya seperti hewan ternak, industri dan hotel merupakan data yang digunakan sesuai dengan wilayah studi yang dikaji. Analisis yang digunakan untuk mengolah data pada umumnya menggunakan persamaan gerarkis dan metode penelitian yang digunakan ialah deskriptif kuantitatif. 
Masing-masing wilayah memiliki luas ruang terbuka hijau yang berbeda-beda, Banda Aceh memiliki ruang terbuka hijau 10,94\%, kota Depok memiliki ruang terbuka hijau sebenyak 25,59\%, kota Denpasar memiliki ruang terbuka hijau sebanyak 38,92\%, kota Manado memiliki ruang terbuka hijau sebanyak 76,25\%, kota Palangkaraya memiliki ruang terbuka hijau sebanyak 29,9\% dan kota Salatiga memiliki ruang terbuka hijau sebanyak $16,31 \%$.

Berdasarkan hasil analisis diantar enam wilayah tersebut hanya terdapat satu wilayah yang sudah memenuhi kebutuhan ruang terbuka hijau berdasarkan oksigen yaitu Kota Manado. Kota manado menggunakan 4 parameter dalam penelitiannya yang terdiri dari kependudukan, kendaraan bermotor, hewan ternak dan hotel. Ke-lima kajian literatur yang lain hanya menggunakan dua sampai tiga parameter. Kesimpulan yang didapat dari 6 kajian literatur tersebut ialah semakin banyak parameter yang digunakan untuk melakukan analisis maka semakin efektif hasil yang didapatkan, sehingga kebutuhan luas ruang terbuka hijau dapat memenuhi kebutuhan oksigen manusia dengan akurat. Saran untuk melakukan studi selanjutnya ialah melakukan analisis kebutuhan ruang terbuka hijau terhadap kebutuhan oksigen dengan menggunakan parameter penelitian sebanyak-banyaknya untuk mendapatkan hasil yang akurat.

\section{DAFTAR PUSTAKA}

Anhusadar, L. O. (2018). Ruang Tebuka Hijau Layak Anak. https://doi.org/10.13140/

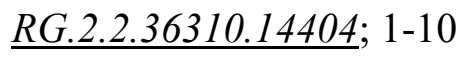

Ardani, Cuak; HanafI, N; Pribadi, T. (2015). Perkiraan Luas Ruang Terbuka Hijau Untuk Memenuhi Kebutuhan Oksigen Di Kota Palangkaraya. Jurnal Hutan Tropis, 1(1), 2-8.

Indah, Andan S.K; Wardiyanti, Tatiek; Setyobudi, L. (2014). Analisa Lanskap Jalur Hijau dan Upaya Penerapan Smart Green Land Pada Ruang Terbuka Hijau. Jurnal Produksi Tanaman, 2(3), 199.

Irham, A., Yulianti, C. S., \& Nizar, M. (2017). Analisis Ketersediaan ruang terbuka hijau Berdasarkan Kebutuhan Oksigen Di Kota Banda Aceh. Jurnal Serambi Engineering, 2(4), 188-196.

Kusminingrum, N. (2008). Potensi Tanaman Dalam Menyerap CO2 Dan CO Untuk Mengurangi Dampak Pemanasan Global. Jurnal Permukiman, 3(2), 96-105. 
Mbele, Maria Febriana B \& Setiawan, R. P. (2015). Penyediaan Ruang Terbuka Hijau Berdasarkan Kebutuhan Oksigen di Kota Malang. Jurnal Teknik ITS, 4(2), 98-101.

Muis, B. A. (2016). Analisis Kebutuhan ruang terbuka hijau Berdasarkan Penyediaan Oksigen dan Air di Kota Depok Provinsi Jawa Barat. Jurnal Rona Teknik, 2(2), 2-14.

Peraturan Menteri Pekerjaan Umum. 2008. Undang-Undang No. 05 Tahun 2008 Yang Membahas Pedoman Penyediaan Dan Pemanfaatan ruang terbuka hijau Di Kawasan Perkotaan. Direktorar Jendral penataan ruang departemen pekerjaan umum Tahun 2008, Jakarta.

Purwatik, Sri; Sasmito, B. H. (2014). Analisis Ketersediaan ruang terbuka hijau (RTH) Berdasarkan Kebutuhan Oksigen (Studi Kasus: Kota Salatiga. Jurnal Geodesi Undip, 3(3), 124-135.

Putra, E. H. (2012). Analisis Kebutuhan ruang terbuka hijau Berdasarkan Pendekatan Kebutuhan Oksigen Menggunakan Citra Satelit EO-1 ALI ( Earth Observer-1 Advanced Land Imager) di Kota Manado. Jurnal BPK Manaoo, 2(1), 41-54.

Putra, I. S., \& Rombang, Johan A; Nurmawan, W. (2018). Analisis Kemampuan Vegetasi Dalam Meredam Kebisingan. Jurnal Eugenia, 24(3), 105-115.

Putrajaya, I. K. (2017). Analisis Indeks Vegetasi Menggunakan Citra Alos Avnir-2 Untuk Estimasi Kebutuhan ruang terbuka hijau Berdasarkan Kebutuhan Oksigen di Kota Denpasar, Provinsi Bali. Jurnal Pendidikan Geogradi, 22(1), 49-59.

Putri, A. R., Yuliani, E., \& Rahman, B. (2019). Pembentukan Ruang Aktivitas Sosial Pada Ruang Terbuka Publik Taman Menteri Supeno. Jurnal Planologi, 14(2), 135-149.

Ramadhan, Gema; Nurzuraida, Gina; Wibowo, Heru; Wijaya, K. (2018). Elemen Pembentuk Ruang Terbuka Publik Alun-Alun Kota Bandung. Jurnal Ensains, 1(1), 56-62.

Rahman, B., Noviani, A., \& Rosyadea, R. (2020). The Effect of Street Vendors' Activities in City Park on the Functions of Park as a Public Space. In Journal of Physics: Conference Series (Vol. 1655, No. 1, p. 012114). IOP Publishing.

Rahman, B., \& Putri, A. R. (2020). The role of Wi-Fi network in producing social space in Mentri Supeno Park Semarang, Indonesia. In IOP Conference Series: Materials Science and Engineering (Vol. 830, No. 2, p. 022082). IOP Publishing.

Rijal, S. (2008). Kebutuhan ruang terbuka hijau di Kota Makassar Tahun 2017. Jurnal Hutan Dan Masyarakat, 3(1), 65-77. 
Setiawan, Agus \& Hermana, J. (2013). Analisa Kecukupan ruang terbuka hijau Berdasarkan Penyerapan Emisi CO2 dan Pemenuhan Kebutuhan Oksigen di Kota Probolingo. Jurnal Teknik Pomits, 2(2), 2013-2016.

Setyati, R. (2015). Implementasi Kebijakan Penataan ruang terbuka hijau Kawasan Perumahan Kota Banjarbaru. Jurnal Kebijakan \& Administrasi Publik (JKAP), 19(1), 59-72.

Shani, Fauzan Maulana \& Kurniawan, A. (2016). Kajian Ketersediaan dan Kebutuhan ruang terbuka hijau Kawasan Perkotaan di Kota Sukabumi. Jurnal Bumi Indonesia, 4(4), 1-8.

Siwi, N. (2018). Pentingnya ruang terbuka hijau dalam Tata Ruang Perkotaan Sebagai Sudut. Jurnal Universitas Muhammadiyah Yogyakarta, 1-15.

Sumarauw, A. N. (2016). Analisis Kebutuhan ruang terbuka hijau Publik di Kota Bitung. Jurnal Berkala Ilmiah Efisiensi, 16(04), 952-961.

Sunaryo, D. K. (2013). Mengetahui Produksi dan Kebutuhan Oksigen Perkotaan Dengan Analisis Lahan Hijau dan Jumlah Penduduk Dengan Memanfaatkan SIG. Jurnal Industri Inovatif, 3(2), 28-31.

Undang-Undang Republik Indonesia 2007. Undang-Undang No. 26 Tahun 2007 Yang Membahas Tentang Penataan Ruang. Jakarta.

Wisesa, S.P.C. (1988). Studi Pengembangan Hutan Kota Di Wilayah Kotamadya Bogor. Skripsi. Jurusan Konservasi Sumberdaya Hutan. Fakultas Kehutanan IPB. Bogor. 